\title{
RUPTURAS E TENSÕES NO PROCESSO DE CONSTITUIÇÃO ESTRUTURAL DO SUBCAMPO ESPORTIVO DO XADREZ (I900-1960)'
}

\author{
MS. JULIANO DE SOUZA \\ Mestre em Educação Física pela Universidade Federal do Paraná e aluno \\ do Programa de Pós-Graduação (Doutorado) em Educação Física \\ da Universidade Federal do Paraná (Curitiba - Paraná - Brasil) \\ E-mail: julianoedf@yahoo.com.br

\section{DR. WANDERLEY MARCHI JÚNIOR} \\ Doutor em Educação Física pela Universidade Estadual de Campinas e \\ Professor da Universidade Federal do Paraná (Curitiba - Paraná - Brasil) \\ E-mail: marchijr@ufpr.br
}

\begin{abstract}
RESUMO
No presente artigo nos propomos em abordar, de um ponto de vista sociológico, a "história esportiva" do xadrez de modo a restituir algumas das rupturas e tensões inerentes ao processo de constituição dessa prática como um subcampo esportivo moderno. Mais precisamente, procuramos apresentar algumas das principais transformações estruturais que foram decisivas no sentido de afirmar o caráter de esportividade da prática enxadrística e legitimar os agentes e estruturas responsáveis pela circulação social do enxadrismo no interior do universo de concorrência esportiva. Para esse desiderato, nos valemos de uma pesquisa de caráter histórico-bibliográfica realizada com base nas literaturas enxadrísticas. No que se refere ao tratamento teórico e construção dos argumentos, tomamos como ponto de partida algumas contribuições tecidas na teoria sociológica de Pierre Bourdieu.
\end{abstract}

PALAVRAS-CHAVE: "História esportiva"; xadrez; esporte; sociologia.

I. A pesquisa da qual este artigo resulta contou com o financiamento REUNI (modalidade bolsa de mestrado). Aproveitamos a oportunidade também para agradecer a disponibilização do material bibliográfico pelo Clube de Xadrez de Guarapuava/PR para a realização da pesquisa de mestrado que deu origem a este artigo. 
As discussões e reflexões que serão brevemente suscitadas neste artigo fazem parte de um conjunto maior de ideias e tessituras que foram desenvolvidas em nossa dissertação de mestrado que teve como título: "O xadrez em xeque: uma análise sociológica da 'história esportiva' da modalidade." (SOUZA, 20 I0). De antemão, convém ressaltarmos que a categoria denominada de "história esportiva" não diz respeito a um conceito puramente abstrato ou hipotético, mas a um recurso analítico empiricamente corroborado e que, portanto, nos permitiu sistematizar e construir uma perspectiva de tratamento sociológico para, num primeiro momento, pensar uma série de transformações e rupturas estruturais que se deram no universo do xadrez e, num segundo momento, demonstrar por que e de que forma essa prática no decorrer do século $X X$ veio a se afirmar e se legitimar, mediante um sistema acirrado de lutas e concorrências, na condição social de esporte moderno.

É importante ser pontuado que essa preocupação de natureza eminentemente teórico-metodológica subsidiada pela possibilidade de resgatarmos o caráter de esportividade da prática enxadrística ao longo de sua história e analisá-la a partir de um referencial sociológico compatível se deu por conta justamente de explicitarmos algumas das razões pelo qual os agentes e estruturas inerentes ao espaço dos produtores do espetáculo a partir de determinado momento histórico, mais especificamente na transição estrutural do século XIX para o XX, reivindicaram o status de esporte moderno para o xadrez ou ainda um lugar estabelecido para a referida prática no interior do campo esportivo em vias de conformação e estruturação.

Dito de outro modo, nossa problemática de pesquisa no que se refere à constituição de uma "história esportiva" do xadrez consistiu particularmente em reunir algumas evidências empíricas, mediante trabalho de natureza historiográfica pautada em uma série de produções literárias acerca da temática, para demonstrar e explicar por que os enxadristas de alto nível e dos principais centros produtores do xadrez mundial já durante as primeiras décadas do século $X X$ procuraram conferir um significado mais esportivo à sua prática de modo a superar, pelo menos em parte, as concepções de xadrez como arte, ciência ou jogo.

No presente artigo apresentamos então alguns fragmentos empíricos subjacentes à nossa abordagem sociológica da "história esportiva" do xadrez (SOUZA, 2010 ), tendo como recorte temporal para este exercício, o período compreendido entre aproximadamente os primeiros anos do século XX e o final dos anos 1960. Esse recorte, por sua vez, foi definido mediante a constatação empírica de que as transformações e rupturas mais decisivas no sentido de consolidar um significado mais esportivizado para a prática enxadrística se deram nas seis primeiras décadas 
do século $X X$. Em síntese, nosso objetivo nesse artigo é apresentar a partir de um registro temporal estruturado, ou seja, em ordem cronológica, algumas das principais transformações estruturais que foram decisivas no propósito de afirmar o caráter de esportividade da prática enxadrística e legitimar os agentes e estruturas responsáveis pela circulação social do enxadrismo no interior do universo de concorrência esportiva.

Para o cumprimento desse objetivo, procuramos sistematizar uma pesquisa de caráter histórico-bibliográfica consubstanciada no mapeamento e retomada de uma série de literaturas enxadrísticas produzidas, em sua maioria, pelos próprios jogadores de xadrez com o intuito de registrar a história de sua prática e, é claro, conferir um maior lucro de distinção material e simbólica a eles próprios. No nosso modo de ver as coisas, essas literaturas são chaves reveladoras de um habitus ao mesmo tempo literário e esportivo intimamente afinado com as condições histórico-estruturais de oferta sistemática do xadrez no interior do campo esportivo, oferta essa, é sempre importante frisar, estruturada sob as pressões políticas e econômicas produzidas no contexto histórico-social aqui problematizado. Daí, portanto, a centralidade dessas literaturas/bibliografias para construção de nossos argumentos.

O referencial sociológico que contribuiu para compreensão dos fatos apresentados é o de Pierre Bourdieu, em particular, com a sua noção de "história estrutural relativamente autônoma do esporte" (BOURDIEU, 1983; 1990) e com o sentido de reflexividade teórico-metodológica conforme discutimos em outro lugar (SOUZA; MARCHI JÚNIOR, 20 I0). Em termos bastante sucintos, a reflexividade teórico-metodológica foi garantida nessa pesquisa mediante o desenvolvimento de uma rigorosa vigilância epistemológica sobre a forma como foi construída a relação pesquisador/objeto e a relação entre teoria e empiria. Além disso, ao revisitarmos algumas das linhas esportivas da história do xadrez tivemos como pressuposto norteador considerar a construção plural e conflitiva do espaço dos pontos de vista, ou seja, do próprio locus onde os enxadristas/literatos puderam retratar o sentido de esportividade recobrado para a prática enxadrística e, acima de tudo, galgar para eles mesmos uma posição de prestígio e visibilidade no interior desse espaço. Feitos esses esclarecimentos, convém avançarmos para a discussão que se constitui como motivo central do artigo.

\section{O SUBCAMPO ESPORTIVO DO XADREZ - ALGUMAS TENSÕES E RUPTURAS}

Um dos principais agentes que reuniu esforços no sentido de que o caráter social e esportivo da prática enxadrística fosse elevado a um maior nível de circulação e legitimação nos campos de produção cultural e na sociedade como um todo, foi, 
sem dúvida, o enxadrista Emanuel Lasker. Nascido em 24 de dezembro de 1868 na pequena cidade de Berlinchen, localizada próxima da então fronteira entre a Prússia e a Rússia, Lasker, mais que um jogador, era um pesquisador do xadrez com doutorado em Matemática e Filosofia. Os seus trabalhos mais significantes são expressos em sua teoria dos jogos e, principalmente, em seu clássico texto, "Manual of chess", publicado originalmente em 1925 (LANDSBERG, 1993).

Diferentemente do enxadrista Wilhelm Steinitz ( 1836 - 1900) - pioneiro de uma escola enxadrística moderna que se contrapunha aos princípios do xadrez clássico -, Lasker não estava preocupado apenas com a sistematização de uma nova escola onde o desenvolvimento de aspectos posicionais e táticos conferisse determinadas vantagens sobre os adeptos do xadrez romântico conhecido, é sempre bom lembrarmos, pelo estilo combinatório e intuitivo de seus jogadores. Para Lasker, uma boa performance não consistia apenas em adotar e obedecer a uma série de leis e princípios estabelecidos durante a partida. Ao contrário, para um desempenho mais efetivo e consistente se fazia também necessário, segundo seu ponto de vista, estudar as características do adversário, de modo que fosse possível criar uma situação no tabuleiro na qual o mesmo se sentisse inseguro (LANDSBERG, 1993; GARCIA, 2006).

Com esse estilo, Lasker conseguiu vencer seis campeonatos mundiais consecutivos, permanecendo com o monopólio do título por 27 anos - a maior sequência da "história esportiva" relativamente autônoma do xadrez. Entretanto, devemos ponderar que Lasker não colocou em disputa seu título entre os anos de 1896 a 1907 por conta basicamente de seus estudos na academia que the demandavam total dedicação e, de 191 | a 1920, porque não conseguiu organizar um match nas condições financeiras e estruturais desejadas. Além disso, de 1914 a 1918, houve o imperativo da Primeira Guerra Mundial, que inviabilizou qualquer negociação mais específica e duradoura no campo esportivo e em outros campos sociais (FINE, 1983; LASKER, 1999).

Outro dado importante a ser mencionado, é que Lasker conseguiu sua estabilização financeira por meio da divulgação de suas reflexões acadêmicas sobre o xadrez através do jornalismo e de palestras proferidas em congressos (FINE, 1983; JOHNSON, 2007). Além disso, seu capital cultural e simbólico² adquirido basicamente

2. Dito de forma bastante sintética, o capital cultural para Bourdieu trata-se de um conjunto de bens expresso principalmente pelo acúmulo de conhecimento, decorrente, primeiramente de uma herança familiar e, em segundo lugar, pela experiência de escolarização dos indivíduos e entregas de certificados e outras consagrações. Já o capital simbólico, diz respeito basicamente ao reconhecimento social da posse de um elevado volume de qualquer outra espécie de capital. Em outros termos, o capital simbólico seria, por exemplo, o capital cultural, social ou econômico reconhecido como vantagem e virtude pelos demais agentes e pares no campo. 
por conta dessas inserções e, claro, de seu desempenho na modalidade, foi tão expressivo a ponto de demarcar significativamente, no período em que se fez presente no referido subcampo esportivo, uma melhora da remuneração e nas condições de realização de eventos e torneios no âmbito do xadrez internacional.

Em 1900, no $12^{\circ}$ Congresso da União de Xadrez da Alemanha realizado em Munique, Lasker ainda presidiu uma reunião com alguns dos principais enxadristas da época e cuja pauta central era fundar uma União dos Maestros Internacionais de Xadrez. O primeiro presidente dessa então associação recém fundada foi Berger e, logo em seguida, Tarrasch em 1902. Todavia, essa organização logo perdeu sua representatividade e se dissipou (KASPAROV, 2004; GARCIA, 2006).

Ao longo de sua trajetória enxadrística, Lasker também sugeriu que fossem dados direitos autorais aos jogadores sobre suas partidas, enxergando nessa medida a base para consolidação de um profissionalismo. Essa reivindicação dos direitos autorais, por sua vez, evidencia que o xadrez para Lasker, mais que um esporte, era como uma obra de arte produzida por um artista profissional. Suas palavras rebatendo àqueles que consideravam que o xadrez não poderia ser tratado profissionalmente são esclarecedoras, nesse sentido:

\footnotetext{
Os milhões de entusiastas que reproduzem as partidas dos mestres, aprendem através delas, e encontram um prazer anímico, não deveriam adotar este ponto de vista. Usando os mesmos argumentos, o mundo da música poderia negar o sustento aos talentosos músicos profissionais, o que seria, evidentemente, injusto. Somente aqueles que se dedicam inteiramente a um assunto particular podem criar algo grande em tal campo (LASKER apud KASPAROV, 2004, p. 213).
}

O raciocínio de Lasker recuperado por Kasparov possibilita o entendimento de que o profissionalismo tratava-se de uma condição indispensável ao desenvolvimento do xadrez de modo que essa prática pudesse atingir, naquele contexto histórico, uma maturidade artística e cientíica. Além disso, devemos frisar que tal concepção de xadrez como manifestação propriamente artística estava excepcionalmente vinculada a pressões de ordem econômica, de modo inclusive a transcender o ideal romanesco "da arte pela arte". Em suma, para Lasker o grau de envolvimento e dedicação ao enxadrismo dependia da quantidade de capital econômico oferecido aos produtores enxadristas no subcampo, assim como a qualidade artística do xadrez à soma dessas duas proposições.

Avançando na exposição dos argumentos, convém lembrarmos que nos anos de 1909 e 1914 foram realizados os torneios de xadrez de São Petersburgo - principal centro de produção cultural da Rússia czarista. Lasker venceu ambos dividindo o primeiro lugar com Akiba Rubinstein em 1909, seguido de Capablanca e 
Alekhine em 19 |4. O czar Nicolau |l da Rússia concedeu aos cinco finalistas da edição do torneio em 19|4 - Emanuel Lasker, José Raúl Capablanca, Alexander Alekhine, Siegbert Tarrasch, e Frank Marshall - o título de Grande Mestre (KASPAROV, 2005). No entanto, esse título só seria formalizado pela Fédération International Des Échecs (FIDE) em 1950, quando a mesma criou uma hierarquia de títulos que seria conferida aqueles jogadores que apresentassem bons resultados diante de outros mestres e grandes mestres do xadrez internacional.

No ano de 1921, Lasker perdeu seu título mundial para o jovem cubano José Raúl Capablanca, considerado um dos mais fortes enxadristas que fez história no subcampo do xadrez. Essa distinção atribuída ao jogador se materializou exatamente porque o mesmo não se preparava para seus jogos, o que, no entanto, não comprometeu seu desempenho e sua efetividade expressa, por exemplo, na invencibilidade que conseguiu manter de 1916 a 1924 quando o enxadrista cubano não sofreu nenhuma derrota sequer (KASPAROV, 2004).

No entanto, em 1927, Capablanca foi derrotado pelo jogador russo Alexander Alekhine. O enxadrista russo superou a "habilidade natural" de Capablanca com sua extensa preparação técnico-tática sobretudo no que tange a análise profunda de aberturas - um diferencial que inclusive se tornaria marca registrada de todos os futuros grandes mestres. Alekhine conseguiu manter o título até 1935 quando o enxadrista e matemático holandês Max Euwe o derrotou pelo placar de 15,5 a 14,5. Entretanto, em 1937 Alekhine conseguiu recuperar o título de campeão mundial em um match revanche contra Euwe e o manteve até 1946, ano de seu falecimento (LASKER, 1999; KASPAROV, 2005).

É importante reiterarmos que até esse período a disputa pelo título de campeão mundial de xadrez era conduzida de modo informal, ou seja, ficava a cargo de acordos estabelecidos entre os próprios enxadristas e eventuais organizações que os mesmos estivessem filiados. Além disso, a realização dos matches pela disputa do título mundial era financiada, sobretudo, pela iniciativa privada que obviamente investia nesses eventos em função do retorno simbólico e material que poderia advir dessas negociações fomentadas no interior do campo esportivo.

Também é oportuno notarmos que a corrida pelos patrocínios e investimentos era uma iniciativa atribuída, invariavelmente, ao jogador desafiante, o que, mais uma vez, reforça o argumento bourdieusiano de que a história estrutural relativamente autônoma do esporte se constitui como importante recurso de leitura daquelas relações materiais e simbólicas que se erguem e são constantemente ressignificadas nos subcampos e campo esportivo. Tal assertiva, por sua vez, está fundamentada no pressuposto de que as leis específicas de funcionamento do subcampo do xadrez, dentre as quais se inclui aquelas pertinentes ao processo de seleção dos campeões 
mundiais, garantiam uma relativa autonomia no gerenciamento dessa prática e na circulação da mesma no mercado de bens simbólicos e culturais.

Com a morte de Alekhine o sistema informal de organização dos matches foi incisivamente prejudicado tendo em vista que as negociações para que o enxadrista russo jogasse um match contra seu compatriota Mikhail Botvinnik já estavam bem adiantadas. Nesse caso, Max Euwe poderia aclamar moralmente a coroa de campeão mundial e, assim, defender o título no lugar de Alekhine. Todavia, o jogador acabou concordando que a FIDE organizasse o próximo confronto para definição do título mundial. Curiosamente, em 1970, esse mesmo Max Euwe seria eleito presidente da referida federação esportiva, cargo em que permaneceu instituído por oito anos consecutivos (KASPAROV, 2005).

Cabe aqui frisarmos que embora a FIDE já houvesse sido fundada em 1924 , a mesma não detinha um potencial de poder suficientemente representativo para impor modificações na estrutura de organização dos campeonatos mundiais. Essa relativa passividade da Fédération International Des Échecs durante as duas primeira décadas de sua fundação se explica basicamente porque a nação enxadrística mais forte do mundo, a União Soviética, recusava a participar de um encontro pela disputa do título mundial que fugisse aos seus interesses e comprometesse de alguma forma a ortodoxia então instaurada no subcampo do xadrez.

Decorre dessa leitura o desvelamento de uma das disputas históricas mais contundentes travadas no interior do referido subcampo esportivo. De um lado, a União Soviética que possuia uma infra-estrutura enxadrística capaz de propor um campeonato mundial à parte monopolizando, dessa forma, a distribuição dos bens materiais e simbólicos no subcampo do xadrez. De outro lado, a FIDE que tinha seu raio de ação e intervenção comprometida pelas tomadas de posição da União Soviética no interior do subcampo esportivo em questão.

É imperativo ressaltarmos que a prática sistemática do xadrez já se fazia presente na Rússia czarista. Todavia, foi por volta de meados de 1920 que se iniciou o processo de massificação dessa prática na União Soviética - uma experiência de popularização esportiva jamais vista no interior de uma mesma sociedade. Essa experiência, inclusive, se possibilitou quando o Partido Comunista assumiu o governo da União Soviética e decidiu adotar o jogo como forma de treinamento mental e preparação para a guerra. $\bigcirc$ xadrez era visto como uma demonstração do materialismo dialético; um jogo que transcendia às lutas entre classes sociais e que, além disso, não era controlado pela ideologia burguesa (JOHNSON, 2007).

O primeiro e, talvez, maior expoente enxadrista formado no interior desse sistema foi Mikhail Moisseievitch Botvinnik. Nascido em I9 I I, doutor em engenharia, Botvinnik liderou a forte escola soviética de xadrez, caracterizada especificamente 
como um sistema profissional de treinamento dos jogadores e expressa, dentre outras coisas, no amplo estudo de aberturas, no conhecimento aprofundado dos finais temáticos e em uma valoração e avaliação acurada das posições de meio de jogo. A escola soviética encabeçada por Botvinnik formou, dentre outros jogadores, os campeões mundiais Anatoly Karpov e Garry Kasparov que dominariam hegemonicamente o xadrez no último quarto do século $X X$.

A primeira aparição de Botvinnik no exterior se deu no torneio de Hastings em 1934, quando obteve uma performance incompatível com seu nível de preparação e treinamento. Após esse torneio, Botvinnik se retirou por dois anos da arena internacional e trabalhou no sentido de corrigir suas deficiências. Quando retornou à arena internacional, no torneio de Nottingham em 1936, Botvinnik ficou em primeiro lugar juntamente com Capablanca - campeão mundial de 1921 a 1927 - e a frente do então campeão mundial Max Euwe e dos ex-campeões mundiais Alexander Alekhine e Emanuel Lasker (FINE, 1983).

No entanto, o domínio soviético no xadrez seria de fato estabelecido pela vitória de Botvinnik no campeonato mundial de 1948, disputado em forma de torneio entre os cinco melhores enxadristas do mundo: Mikhail Botvinnik, Vasily Smyslov e Paul Keres representando a União Soviética, Samuel Reshevsky representando os Estados Unidos e, finalmente, Max Euwe, representando a Holanda. O referido torneio foi organizado pela FIDE que, com o apoio da URSS, declarou a vacância do título mundial do período de 1946 até 1948 (KASPAROV, 2005).

Cabe notarmos que essa aproximação da União Soviética à FIDE pode ser entendida como estratégica já que sua estrutura e infra-estrutura enxadrística, no referido momento, estava preparada e pronta para enfrentar qualquer adversário (condição essa que não deixa de ter uma forte correlação com os imperativos da Guerra Fria que se ensaiava no palco social). Note-se que esse triunfo do comunismo manifesto no subcampo do xadrez foi perpetuado hegemonicamente por mais de duas décadas, quando então um enxadrista norte-americano quebrou essa sequência de títulos mundiais acumulados pelos enxadristas soviéticos.

Sobre a estrutura do xadrez na União Soviética é oportuno notarmos que a mesma representava e ainda representa (na figura da Rússia, Armênia e Georgia, por exemplo), a posição dominante no subcampo do xadrez. E isso exatamente porque a referida nação conseguiu, com base no idealismo comunista, massificar a prática entre crianças, adolescentes e trabalhadores de modo a reunir e sitematizar um exército de milhões de jogadores (JOHNSON, 2007). Notemos ainda que essa estratégia de massificação seria adotada em outras práticas esportivas na União Soviética e, além disso, transferida para outros países de orientação socialista. Segundo os pesquisadores David Edmonds e John Eidinow (2007, p. 60-61), calcula-se que em 1923 só haviam 
mil jogadores de xadrez registrados na União Soviética. Em 1929, por sua vez, esse número aumentou para I 50 mil, atingido em 195 I, o número de um milhão de jogadores filiados e em meados de 1960 cerca de três milhões.

A partir dessas estratégias de massificação é que seriam descobertos os talentos enxadrísticos, os quais, segundo a ideologia comunista, deveriam se tornar funcionários do Estado com a missão coletiva de enriquecimento esportivo, além de envolvimento em trabalhos intelectuais e analíticos, exibições em partidas simultâneas e oferta de cursos especializados (FINE, 1983; JOHNSON, 2007). Outro dado que expressa o lugar de destaque ocupado pelo xadrez no interior da cultura soviética se estabelece na medida em que consideramos que todas as empresas, sindicatos, clubes, seções de exército, tinham suas próprias equipes de xadrez que disputavam entre si fortes torneios e competições a nível nacional (KASPAROV, 2005; EDMONDS; EIDINOW, 2007).

Além disso, conforme a grande campanha soviética de massificação e treinamento dava frutos, culminando com a formação de centenas de jogadores que atingiam o nível de mestre ou grande mestre entre os anos 1940 e 1960, um amplo sistema de recompensas e punições foi estruturado e estendido ao subcampo do xadrez. Se por um lado, a vida de um profissional do xadrez era privilegiada com remunerações mais altas do que os salários médios dos "cidadãos comuns" e com viagens ao exterior que lhes eram permitidas, por outro, esses mesmos jogadores tinham suas vidas mais expostas às censuras políticas o que, inclusive, incluía o préstimo de conta ao governo sobre suas atuações comprometedoras no exterior (JOHNSON, 2007; EDMONDS; EIDINOW, 2007). Por sua vez, essa rígida inspeção e fiscalização imposta pelo Partido Comunista ao xadrez profissional soviético não foi suficiente para ausentar o sistema de tomadas de posições individualistas, como o caso, por exemplo, do enxadrista Boris Spassky que nem sequer chegou a se filiar ao referido partido (EDMONDS; EIDINOW, 2007, p. 86).

Retomando o torneio de 1948, convém notar que o mesmo demarcou uma ruptura no subcampo esportivo do xadrez de modo a aproximar a URSS da Fédération International Des Échecs para então eleger o primeiro campeão mundial de xadrez da chamada "era FIDE". A disputa do torneio, como foi dito anteriormente, se deu entre cinco jogadores que se enfrentaram todos contra todos em matches de cinco partidas. Dos seus vinte pontos possíveis, Botvinnik somou 14 pontos, Smyslov I I, Keres e Reshevsky I 0,5 e Euwe 04 pontos. Indiscutivelmente e com base nos escores apresentados, podemos dizer que Botvinnik foi superior aos seus adversários. No entanto, alguns comentaristas insistem na hipótese de que seu compatriota Paul Keres sofreu pressões das autoridades soviéticas para entregar suas partidas a Botvinnik (SAYD, 1972; FINE, 1983). 
Após o referido torneio de 1948, a FIDE obteve o monopólio da organização dos campeonatos mundiais. Não obstante, no lugar do sistema informal anterior, um novo sistema de torneios qualificatórios foi preparado. A disputa do título mundial deveria ser realizada em ciclos de três anos, sendo que os aspirantes seriam definidos mediante um sistema burocrático e altamente racionalizado. Esse sistema adotado pela FIDE, dividiu o universo enxadrístico, ou melhor, o subcampo do xadrez em oito zonas: Europa Ocidental, Europa Oriental, União Soviética, Estados Unidos, Canadá, América do Sul e Austrália. Posteriormente, outras duas zonas foram incorporadas: Europa Central e Ásia Ocidental (GONZÁLEZ, 1972, p. 09-10).

No interior de cada uma dessas zonas se realizariam os chamados "torneios zonais", que definiriam os jogadores, segundo as cotas reservadas em cada zona, para disputar o "torneio interzonal". Os principais finalistas do torneio interzonal, por sua vez, participariam do "torneio de candidatos", inicialmente realizado no sistema todos contra todos e a partir de 1965 no sistema eliminatório de partidas. O vencedor do torneio de candidatos iria então disputar uma série de partidas com o atual campeão pela disputa do título mundial (GONZÁLEZ, 1972, p. 10). Em todo caso, se o campeão fosse derrotado, ele teria o direito de se juntar ao seu sucessor e ao futuro desafiante na próxima disputa do título. Todavia, em 1957 essa regra foi mudada para permitir que o campeão derrotado disputasse uma revanche um ano após sua derrota.

Respaldado nesse sistema, Botvinnik acabaria sendo presença constante nas disputas dos títulos mundiais por mais de dez anos. Nos seis primeiros anos, Botvinnik defendeu com sucesso seu título duas vezes, derrotando respectivamente David Bronstein em 195I e Vasily Smyslov em 1954. Ambas as disputas terminaram empatadas em 12 a 12, mas, de acordo com as regras estabelecidas pela FIDE, Botvinnik deveria manter o título por ser o atual campeão (KASPAROV, 2005).

Entretanto, em 1957, Smyslov venceu seu conterrâneo pelo placar de 12,5 a 9,5, se tornando o novo campeão-mundial. Por sua vez, em 1958, Botvinnik teve o direito de revanche e recuperou novamente sua coroa com o placar de 12,5 a 10,5 em seu favor. Em 1960 novamente Botvnnik seria superado. Desta vez, pelo enxadrista letão Mikhail Tal. A ousadia e o estilo de sacrifícios imprimido por Tal levou-lhe ao sucesso, sobrepujando Botvinnik pelo placar de I2,5 a 8,5. Todavia, em I96 I, mais uma vez Botvinnik recuperaria seu título com o placar de 13 a 8 (SAYD; LESSING, 1974).

Botvinnik viria a jogar apenas mais um match pelo campeonato mundial, contra o armeno Tigran Petrosian, perdendo de 12,5 a 9,5 no ano de 1963. Nessa oportunidade não houve revanche, porque a FIDE havia abolido essa regra. Botvinnik então se retirou dos campeonatos de xadrez e preferiu se ocupar então com a prática enxadrística por computadores e com a sistematização de sua escola de xadrez, a qual, futuramente, revelaria e ajudaria a formar alguns dos maiores expoentes do enxadrismo soviético e mundial. 
No campeonato mundial de 1966, Petrosian defendeu o título diante de seu conterrâneo Boris Spassky, vencendo-lhe por uma pequena margem de I 2,5 a I I,5, em um match histórico protagonizado na cidade de Moscou. Três anos depois, os jogadores voltaram a se enfrentar. A cerimônia de abertura do match se deu no Teatro da Televisão de Moscou para que a população soviética pudesse acompanhá-la. Com seis vitórias, quatro derrotas e treze empates, Spassky venceu a Petrosian por 12,5 a 10,5 (EDMONDS; EIDINOW, 2007, p. 7I-72). No entanto, em 1972, esse mesmo Spassky - o primeiro campeão mundial soviético que teve que defender seu título contra um aspirante que não era de seu país - viria a ser derrotado pelo norte-americano Robert James Fischer no chamado "match do século", conforme discutimos allhures (SOUZA; STAREPRAVO; MARCHI JÚNIOR, 2009).

\section{CONSIDERAÇÕES PARA O FECHAMENTO}

A preocupação com a historicidade da formação do subcampo esportivo do xadrez se fez central na abordagem sociológica que aqui procuramos empreender, de modo inclusive que foi por conta justamente desta retomada que pudemos avançar na compreensão de alguns episódios e fatos sociais manifestos sob o aspecto de rupturas e descontinuidades históricas no universo enxadrístico entre os anos de 1900 a 1960. Nesse movimento de articulação entre os dados empíricos e a abordagem teórica delimitada, pudemos estabelecer uma narrativa que embora construída em linha cronológica e de forma linear, nos apresenta, por via de algumas das principais disputas materiais e simbólicas protagonizadas entre os agentes e instituições no subcampo esportivo do xadrez, como que se estruturou devidamente esse espaço de lutas, coerções e giro de capitais e, além disso, como se constituíram e se definiram algumas das relações de esportividade nesse universo e no próprio campo esportivo como um todo.

Devemos lembrar, nesse sentido, que o que a partir de um contexto muito específico que abrangeu uma série de transformações sociais que tiveram lugar na Inglaterra e que repercutiram consideravelmente na esfera esportiva na transição do século XIX para o XX, estamos a identificar na condição de uma "história esportiva" da modalidade, com efeito, conserva como seu principal atributo o fato de operar e ativar mecanismos simbólicos e emocionais por vias descontínuas articuladas segundo a lógica de disputas, tensões e, principalmente do reconhecimento de uma legitimidade cultural atrelada ao enxadrismo e seus produtores - leia-se capital cultural reconhecido e, dessa maneira, convertido em capital simbólico - como critério estruturante de entrada da modalidade no universo esportivo.

Em outras palavras e de forma bastante sintética, podemos dizer que o que conferiu, portanto, a entrada estrutural da modalidade de xadrez no universo de 
concorrência esportiva sob as pressões político-econômicas do contexto histórico-social aqui problematizado (1900-1960), foi, num primeiro momento, a importância gradativa conferida ao chamado "capital enxadrístico" - produto das lutas e rupturas estruturais que exploramos rapidamente no decorrer do texto - e, numa etapa complementar e correlata, a conversão deste "capital enxadrístico" em capital simbólico garantido e constituído mediante o reconhecimento dos pares em concorrência no campo esportivo pelas posições de visibilidade, prestígio e, muito particularmente, pela regulação das leis de oferta e demanda que se aplicam a este espaço.

Decorre, por conseguinte, dessa leitura sobre a conformação do "capital enxadrístico", a conclusão de que a "história esportiva" do xadrez aqui reivindicada é a própria história de constituição do respectivo subcampo - um dos primeiros subcampos esportivos modernos a se formar, diga-se de passagem - ainda que não ao modo necessariamente estrutural como Bourdieu pleiteia (SOUZA, 20 I 0). Entretanto, essa história estrutural relativamente autônoma do esporte tal como retomada na obra de Bourdieu ( 1983; 1990) não foi aqui tratada de forma secundarizada, até porque é a partir da descontinuidade que a mesma evoca que pudemos minimamente recuperar leis de reprodução social perpetuadas sob a forma de fundamentos ocultos de dominação nos universos sociais que aqui estiveram em tela.

No caso da discussão suscitada neste artigo, esse tipo de proposta teve seu equivalente no desvelamento de que a constituição e legitimação do xadrez como esporte moderno contribuiu para fundar um mercado esportivo que, ao expandir seu raio de ação mediante a imposição de um arbitrário cultural como unidade fundadora do mundo, conduziu os agentes e grupos sociais vinculados à modalidade ao desconhecimento das causas e efeitos de seus próprios comportamentos consumistas. Colocado em outros temos, o principal desdobramento em evidência nesse microcosmo esportivo revisitado foi, portanto, a formação de um habitus enxadrístico menos pelo que a modalidade representava ou trazia de atrativo em si e mais pelas demandas sensacionalistas do mercado.

Como última observação, é importante reiterar que nesse artigo procuramos nos ater, sobretudo, aos contornos esportivos da modalidade de xadrez tal como delineados no âmbito do profissionalismo e dos principais centros produtores do xadrez mundial. Essa retomada, por conseguinte, é sociologicamente útil na medida em que para entendermos e avaliarmos a circulação social do xadrez e as relações sociais inerentes ao desenvolvimento dessa prática nos mais variados contextos e cenários mundiais bem como a oferta enxadrística no âmbito escolar ou então do lazer, devemos, antes de tudo, compreender como se deram essas relações no espaço dos produtores, já que muito provavelmente existe uma reprodução social inventiva que se estabelece da esfera do profissionalismo para a do amadorismo. Além disso, devemos notar que a reprodução a que aqui nos referimos é muito menos dos contornos sociais da prática enxadrística em si mesma e muito mais da estrutura de poder e dominação que a engendrou 
historicamente nos centros produtores de xadrez mundial segundo as vias de constituição de um mercado esportivo global e de um estilo de vida esportivo adjacente.

\section{Breaks and tensions in the process of construction structural subfield sports of chess (1900-1960)}

ABSTRACT: In this article we intend to address, from a sociological point of view, the "sports history" of chess in order to restore some of the ruptures and tensions inherent in the process of setting up practice as a subfield of modern sports. More precisely, we present some of the major structural changes that were decisive in order to affirm the practice of sportsmanship in chess and legitimate agents and social structures responsible for movement of the chess player inside the world of competitive sports. To this aim, we make use of a research of historical literature was conducted based on chess literature. With regard to treatment theoretical and construction of arguments, we take as a starting point some contributions woven into the sociology theory of Pierre Bourdieu.

KEYWORDS: "Sports history"; chess; sport; sociology.

\section{Rupturas y tensiones en el proceso de construción estructurale del subcampo deportivo de lo ajedrez (1900-1960)}

RESUMEN: En este artículo se pretende abordar, de un punto de vista sociológico, la "historia deportiva" del ajedrez con el fin de restaurar algunas de las rupturas y las tensiones inherentes al proceso de creación de la práctica como un subcampo deportivo moderno. Más precisamente, se presentan algunos de los principales cambios estructurales que fueron decisivas para afirmar el caracter de la deportividad de la práctica ajedrecistica y legitimar los agentes y las estructuras sociales responsables del movimiento sociale del ajedrez dentro del mundo de los deportes competitivos. Para ello, hacemos uso de una investigación histórico y bibliográfica que se llevó a cabo sobre la base de la literatura de ajedrez. En lo que respecta al tratamiento y la construción de argumentos teóricos, tomamos como punto de partida algunas de las contribuciones tejida en la teoría sociología de Pierre Bourdieu.

PALABRAS CLAVE: "Historia deportiva"; el ajedrez; el deporte; sociología.

\section{REFERÊNCIAS}

BOURDIEU, P. "Como é possível ser esportivo?" In: . Questões de sociologia. Rio de Janeiro: Marco Zero, 1983. p. I36-I53.

"Programa para uma Sociologia do Esporte". In: . Coisas ditas. São Paulo: Brasiliense, 1990. p. 207-220.

EDMONDS, D.; EIDINOW, J. Bobby Fischer se fue a la guerra: el duelo de ajedrez más famoso de la historia. Buenos Aires: Debate, 2007. 
FINE, R. The world's great chess games. New York: Dover Publications, 1983.

GARCIA, F. Steinitz and the inception of modern chess. GradExpo, University of Pittsburgh, 2006. Disponível em: <http://www.fedegarcia.net/writings/steinitz.pdf > Acesso em: 17 out. 2009. GIUSTI, P. História ilustrada do xadrez. São Bernardo do Campo/SP: Paulo Giusti, 2002.

GONZÁLEZ, J. M. Y ahora Bobby Fischer Campeón del mundo - I I de julio al I de septiembre de 1972. Madrid: Gráficas BAS, 1972.

JOHNSON, D. White king and red queen: how the Cold War was fought on the chessboard. London: Atlantic Books, 2007.

KASPAROV, G. Meus grandes predecessores I: uma história moderna sobre o desenvolvimento do jogo de xadrez. Santana de Parnaíba/SP: Editora Solis, 2004.

Meus grandes predecessores 2: uma história moderna sobre o desenvolvimento do jogo de xadrez. Santana de Parnaíba/SP: Editora Solis, 2005.

LANDSBERG, K. William Steinitz: a biography of the Bohemian Caesar. Jefferson, N. C.: McFarland \& Co., 1993.

LASKER, E. História do xadrez. 2. ed. São Paulo: IBRASA, 1999.

SAIDY, A. The Battle of Chess Ideas. London: Batsford, 1972.

SAIDY, A.; LESSING, N. The world of chess. New York: Ridge Press \& Randon House, 1974.

SOUZA, J. O xadrez em xeque: uma análise sociológica da "história esportiva" da modalidade. 20 I 0. I 9 If. Dissertação (Mestrado em Educaçaõ Física) - Departamento de Educação Física, Universidade Federal do Paraná, Curitiba, 2010.

SOUZA, J.; MARCHI JÚNIOR, W. Por uma sociologia reflexiva do esporte: considerações teórico-metodológicas a partir da obra de Pierre Bourdieu. Revista Movimento, Porto Alegre, v. 16, n. I, p. 293-315, jan/mar. 2010.

SOUZA, J.; STAREPRAVO, F; MARCHI JÚNIOR, W. A inserção do xadrez no campo esportivo e a lógica mercantil da oferta enxadrística em 1972. Esporte e Sociedade, Rio de Janeiro, v. 13, p. 0I-27, nov. 2009.

Recebido em: 15 nov. 2010 Aprovado em: 12 jun. 201 I

Endereço para correspondência: Juliano de Souza Rua José Zagonel Passos, 460 Vila Bela Guarapuava-PR CEP: 85.027-II0 